\title{
Inclusion of People with Disabilities in Research to Improve Medication Adherence: A Systematic Review
}

\section{Jaclyn K Schwartz' \\ Elizabeth Unni ${ }^{2}$}

'Florida International University, Nicole Wertheim College of Nursing and Health Sciences, Occupational Therapy Department, Miami, FL, USA; ${ }^{2}$ Touro College of Pharmacy, Social Behavioral and Administrative Science, New York, NY, USA
Correspondence: Jaclyn K Schwartz Florida International University, Nicole Wertheim College of Nursing and Health Sciences, Occupational Therapy

Department, Miami, FL, USA

Tel: +I-305-348-3106

Email jaclyn.schwartz@fiu.edu

\begin{abstract}
People with disabilities have high rates of chronic health conditions and often require complex medication regimens to manage their health. Approximately $20-50 \%$ of people with disabilities fail to take their medication as prescribed. It is unclear, however, to what extent the literature describes the effectiveness of medication adherence interventions for people with disabilities. In this review, the inclusion and exclusion criteria of the 182 studies included in the Cochrane Review on Interventions for Enhancing Medication Adherence were evaluated for their inclusion of people with disabilities. Of the studies, $1 \%$ excluded persons for hearing impairment, $3 \%$ for motor impairment, $7 \%$ for visual impairment, and 32\% for cognitive impairment. Most studies (65\%) did not exclude persons based on specific impairment. Medication event monitoring systems were used in $21 \%$ of studies, and investigators excluded people unable to use this device in 5\% of studies. Caregiver assistance was an exclusion criteria in $4 \%$ of studies. Additional barriers like the ability of investigators to exclude persons based on their judgement were found. These barriers exist in addition to the known barriers affecting persons with disabilities, such as accessibility of research facilities and access to transportation. These data suggest that people with disabilities are systemically excluded from the medication adherence intervention literature. Subsequently, it cannot be assumed that current adherence interventions are effective for people with disabilities. More research is needed to understand how to address medication adherence for people with disabilities.
\end{abstract}

Keywords: disabled persons, health services for persons with disabilities, medication adherence, cultural diversity, clinical trials as a topic

\section{Introduction}

Internationally, over 1 billion people live with some form of disability, representing about $15 \%$ of the world's population. ${ }^{1}$ The number of people with disabilities is increasing due to demographic shifts and the increase in prevalence of chronic health conditions. ${ }^{1}$ People with disabilities require medications to address their disability, in addition to the typical medications associated with the general population. For example, people with spinal cord injury require medications to address pain, spasticity, spasms, and bowel and bladder function associated with the injury. ${ }^{2}$ To manage comorbid conditions associated with spinal cord injury, it often requires medications to address diabetes, heart disease, depression, anxiety, etc. As these conditions are comorbid, people with spinal cord injury often begin taking these chronic condition medications earlier in their lives than people without disability. ${ }^{2}$ While this was an example in spinal cord injury, this experience is common across disability groups. ${ }^{3-8}$ 
Given the broad health needs, it is not surprising that people with disabilities take many of medications. People with stroke average 11.3 medications, ${ }^{9}$ people with multiple sclerosis average 5.7 medications, ${ }^{5}$ and people with arthritis average 5.5 medications. ${ }^{6}$ While these are averages, many people with disabilities meet the criteria for polypharmacy (the prescription of 5 or more medications), including $56 \%$ of people with spinal cord injury. ${ }^{2}$

Much like the general population, people with disabilities also have difficulty taking their medications as prescribed. Medication adherence rates are estimated at $49.5 \%$ for people with intellectual disability, ${ }^{4} 65.6 \%$ for people with stroke, ${ }^{3} 60-80 \%$ for people with multiple sclerosis, ${ }^{8}$ and $60-80 \%$ for people with arthritis. ${ }^{7}$

Despite the significant number of people with disabilities, the importance of adherence to medication, and the rates of poor adherence in these populations, disabilityspecific diagnoses are not often studied. In the Nieuwlaat and colleagues (2014) Cochrane Review on Interventions for Enhancing Medication Adherence, the most commonly studied conditions were chronic conditions including HIV/ AIDS, psychiatric disorders, chronic obstructive pulmonary disease, cardiovascular disease or risk, hypertension, and diabetes. In fact, researchers have a history of excluding specific populations from research studies, such as women, minorities, and the elderly in research. ${ }^{11-14}$ Minorities, women, and the elderly are also more likely to experience disability than their white male counterparts. ${ }^{15}$ Clinical trials research suggests that while specific populations are excluded at times, more often there are systemic barriers in the research process or inclusion criteria that prevent participation from these populations. ${ }^{16}$ Barriers found to hinder clinical trial participation include mistrust from the research participant, lack of comfort with the process, lack of information, time and resource constraints, lack of awareness of the study, and failure to meet eligibility criteria. ${ }^{12,17}$

Taken together, this evidence suggests that people with disabilities may be underrepresented in the medication adherence literature. The purpose of this study is to identify and quantify barriers to participation in medication adherence intervention studies from the current literature.

\section{Materials and Methods}

In this systematic review, we completed a secondary analysis of inclusion and exclusion criteria of articles included in the Cochrane Review on Interventions for Enhancing Medication Adherence. ${ }^{10}$ This seminal article is the fourth edition of the review by this authorship team with the Cochrane system. It was chosen as it is the definitive guide on medication adherence interventions.

\section{Instrumentation}

A priori, the research team made a list of criteria that could exclude people with disabilities (Table 1). Researchers reviewed if people with disabilities were excluded

Table I Criteria Excluding

\begin{tabular}{|c|c|}
\hline Criteria & $\begin{array}{l}\text { Definition } \\
\text { Examples of exclusion criteria from studies }\end{array}$ \\
\hline $\begin{array}{l}\text { Hearing } \\
\text { impairment }\end{array}$ & $\begin{array}{l}\text { Excludes people on the basis of their ability to hear. } \\
\text { Includes considerations for Deaf community like } \\
\text { use of Sign Language. } \\
\text { Unable to hear, conditions impairing telephone } \\
\text { communication }\end{array}$ \\
\hline $\begin{array}{l}\text { Motor } \\
\text { impairment }\end{array}$ & $\begin{array}{l}\text { Excludes people on the basis of upper or lower } \\
\text { extremity motor impairment. } \\
\text { Disabled, unable to walk, unable to write, serious physical } \\
\text { alteration, motor problems, mobility problems }\end{array}$ \\
\hline $\begin{array}{l}\text { Vision } \\
\text { impairment }\end{array}$ & $\begin{array}{l}\text { Excludes people who have poor vision or blindness } \\
\text { Unable to read, vision impairment, serious sensory } \\
\text { alteration, legally blind, has specific visual diagnosis (eg } \\
\text { exclusion of persons with diabetic retinopathy in astudy } \\
\text { of adults with Type } 2 \text { diabetes mellitus) }{ }^{18}\end{array}$ \\
\hline $\begin{array}{l}\text { Cognitive } \\
\text { impairment }\end{array}$ & $\begin{array}{l}\text { Excludes people with cognitive impairment } \\
\text { Metal problems, mental illness, inability to give } \\
\text { informed consent, unable to understand intervention or } \\
\text { assessment, poor cognitive function, mental retardation, } \\
\text { fails to meet threshold score on cognitive exam }\end{array}$ \\
\hline $\begin{array}{l}\text { Caregiver } \\
\text { assistance }\end{array}$ & $\begin{array}{l}\text { Excludes people who require assistance from } \\
\text { a friend or family member to consent to the study } \\
\text { or complete study related activities. } \\
\text { Unable to take primary responsibility for taking their } \\
\text { own medications }\end{array}$ \\
\hline MEMS & $\begin{array}{l}\text { Excludes people who are unable to unwilling to use } \\
\text { MEMS } \\
\text { Willing and able to use MEMS }\end{array}$ \\
\hline Other criteria & $\begin{array}{l}\text { Criteria by the research team other criteria that } \\
\text { can be discriminatory } \\
\text { The researcher considered that the patient's health } \\
\text { would be compromised due to adverse effects or } \\
\text { concomitant diseases, patients with diseases that could } \\
\text { interfere with the study, patients whose pathological } \\
\text { situation could interfere with the development of the } \\
\text { study, chronic medical condition, psychological } \\
\text { instability }\end{array}$ \\
\hline
\end{tabular}

Notes: The italics denote a sub description and differentiates the definition from the examples. 
specifically because of their diagnosis or impairment. Specifically, researchers denoted if persons with specific diagnoses or visual, hearing, motor, or cognitive impairment were excluded. Researchers investigated other criteria that may uniquely impact people with disabilities. For example, Medication Event Monitoring Systems Caps (MEMS Caps) are the gold standard for measuring medication adherence, but many people with disabilities have difficulty using this technology. Therefore, the researchers quantified the number of studies using MEMS caps and the number of people excluded because they were unable or unwilling to use MEMS caps. The researchers also quantified the number of studies, excluding persons using caregiver assistance for medication tasks. Finally, the researchers noted other criteria that could exclude people with disabilities.

\section{Procedures}

Full copies of each article included in the Cochrane Review on Interventions for Enhancing Medication Adherence were attained by the research team. ${ }^{10}$ A rating process similar to that described by Tilson and colleagues was used to review each article. ${ }^{19}$ Specifically, two researchers reviewed the articles separately with a specific focus on their inclusion and exclusion criteria, as well as their recruitment strategies using the questionnaire in the instrumentation section. The researchers compared their findings and discussed any discrepancies until they reached a consensus.

\section{Data Analysis}

The purpose of this study was to describe the nature and prevalence of exclusionary criteria. Descriptive statistics were tabulated to describe the prevalence of each criteria.

\section{Results}

All 182 studies included in the Cochrane Review on Interventions for Enhancing Medication Adherence were reviewed against the a priori criteria. ${ }^{10}$ Of the studies, $1 \%$ $(n=2)$ excluded persons for hearing impairment, $3 \%(n=5)$ for motor impairment, $7 \%(\mathrm{n}=12)$ for visual impairment, and $32 \%(\mathrm{n}=58)$ for cognitive impairment (Figure 1). Most studies $(\mathrm{n}=119,65.38 \%)$ did not specify requirements for hearing, motor, vision, or cognitive skills, even if these skills were required for participation in the study. For example, in the study by Mullan and colleagues, one of the main activities included reading decision aids, but people with visual or mild cognitive impairments were not excluded from the study. ${ }^{20}$ Eight studies (4.40\%) excluded participants who required caregiver assistance. About $21 \%$ of studies $(n=38)$ used MEMS to monitor medication adherence. However, only about $5 \%$ of those studies had the ability and/or willingness to use the MEMS device as an exclusion or inclusion criteria (Figure 2).

There were several other study criteria that had the potential to be exclusionary to persons with disabilities. Many studies indicated that the participants were required to provide written informed consent, but it is unclear what

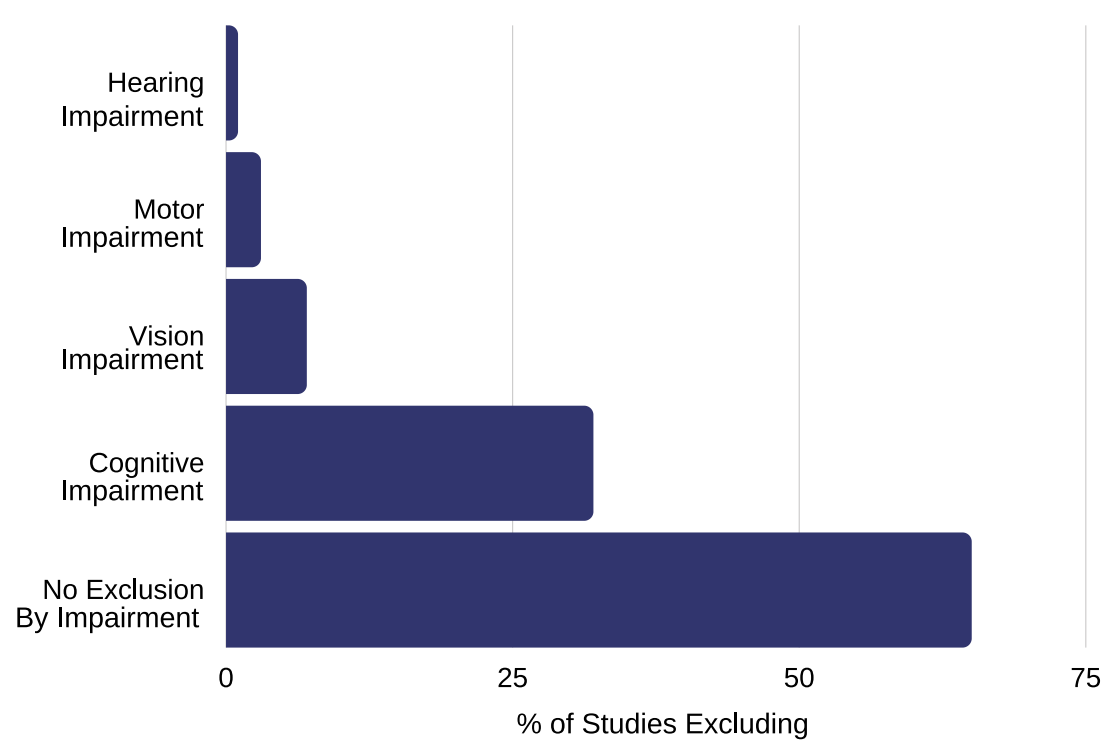

Figure I Percent of studies excluding people with disabilities by impairment. 


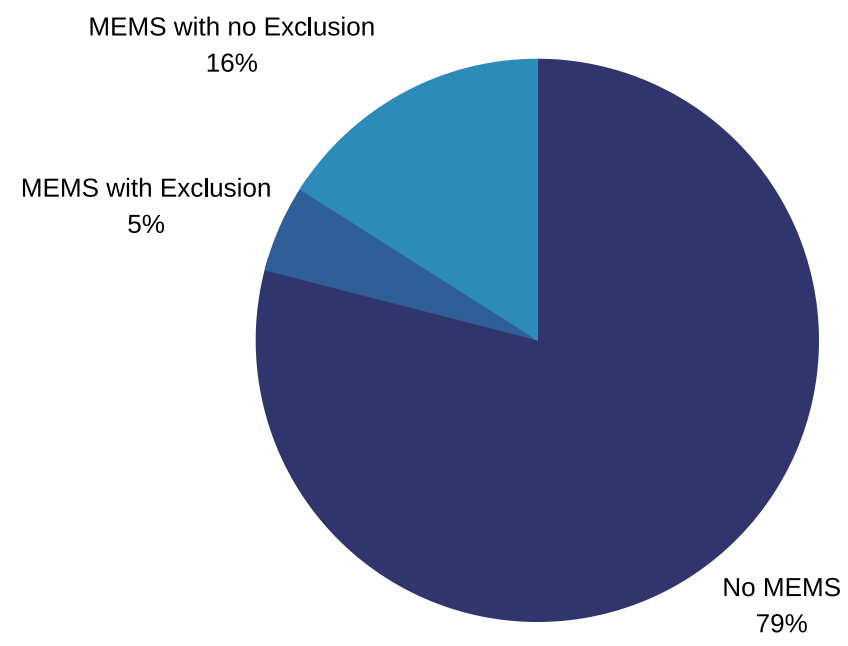

Figure 2 Use of Medication Event Monitoring System (MEMS) in medication adherence intervention research and MEMS as an exclusion criteria.

that means or what level of assistance or accommodation could be provided as part of the informed consent process. Again in the example by Mullan and colleagues where participants were required to read decision aids, ${ }^{20}$ the authors did denote that participants were required to be "able and willing" to provide informed consent. However, it is unclear what level of accommodations could be attained in the informed consent process. In addition to requirements around the informed consent, other studies excluded participants whose prescribed medication regimen exceeded a certain number. ${ }^{20,21}$

Often the research protocols contained criteria that allowed the research team to make judgement calls about the appropriateness of research participants. Many criteria were vague, for example, Márquez Contreras and colleagues excluded "patients whose pathological situation could interfere with the development of the study." 22 Some authors included more information about the process for exclusion. For example, Johnson and colleagues reported that

severe neuropsychological impairment and psychosis were assessed on a case-by-case basis by interviewers in consultation with senior project personnel, including the principal investigator, a licensed clinical psychologist. ${ }^{23}$

Rarely, the research team described the criteria objectively and described how they would seek to accommodate individuals with disabilities. For example, Bennett and colleagues reported that primary care physicians were given a list of research participants and were asked

to exclude patients whom they believed would be unable to monitor their blood pressure or follow medication titration instructions due to physical or cognitive disability, psychiatric illness, or other reasons. ${ }^{24}$

However, they did attempt to make accommodations for persons with disabilities. They reported that they included

patients with reduced cognition ... if they have a known caregiver, such as a family member, capable of assisting the patient with home blood pressure monitoring and medication titration, and speaking with the health coach each week.

\section{Discussion}

Medication adherence is essential to $15 \%$ of people worldwide who require medication to manage their disability and co-morbid medical conditions. ${ }^{1}$ The recent literature about clinical trials diversity, equity, and inclusion suggests that people with disabilities may be participating in medication adherence research at lower rates than their peers with chronic conditions alone. Given the lack of specific data, the purpose of this study was to identify and quantify barriers to participation in medication adherence intervention studies.

The data from this study suggests that people with disabilities are systemically excluded from the research on interventions for medication adherence using two mechanisms. The first mechanism is explicit exclusion on the basis of disability status. The research team looked for studies specifically excluding people with disabilities due to their impairments in hearing, motor, vision, and cognitive skills and found that $34 \%$ of studies excluded persons based on these disabilities.

The second mechanism precluding participation of people with disabilities' in medication adherence research is bias. Several studies included vague criteria that allowed the investigative team to exclude persons who they deemed "unable to complete study activities." This gives the research team carte blanche to determine if they will include people with disabilities in the study. Given the biases and record of poor care from members of the medical community towards members of the disability community, it is unlikely that this process would favor the inclusion and appropriate treatment of persons with disabilities. $^{26,27}$

These findings are consistent with other work in this area. ${ }^{12,16,17}$ This suggests that the issues of including people with disabilities' in research go beyond the medication adherence literature. 


\section{Implications for Research}

It is understandable that investigators want to ensure that the participants could complete study-related procedures. It is also important for people with disabilities to have access to effective medication adherence interventions, and this means the inclusion of people with disabilities in medication adherence research. There are several steps researchers can take to improve representation of people with disabilities' in the research.

Researchers can use purposeful well-thought-out inclusion and exclusion criteria. Data from this study demonstrated two issues. First were studies that unnecessarily excluded people based on ability status unrelated to the research protocol (eg the need to walk for a home blood pressure monitoring program). ${ }^{25}$ Second were studies that failed to excluded people on abilities that were needed to complete the study. MEMS caps serve as a good example. MEMS caps are the gold standard measurement for medication adherence research and 38 (20.88\%) studies reported used this technology. MEMS caps require good hand dexterity and preclude the use of a pillbox, which is a common adaptation used by persons with cognitive impairments. Subsequently, the use of MEMS is anticipated to uniquely negatively impact people with disabilities. When MEMS are used in a study, often they are one of the primary outcome measures. Therefore, it is perplexing that only $30 \%$ of studies with MEMS had their use as a criteria for participation, and it is unclear how investigators would address persons with disabilities who are unable or unwilling to use a MEMS cap. When there is a mismatch between the inclusion criteria and the capacity to participate in the study, this means that either people with disabilities are not participating in research or investigators are excluding persons outside of their inclusion and exclusion criteria. These finding suggest that medication adherence investigators need to more thoughtfully and intentionally conceptualize inclusion and exclusion criteria as to not over or under exclude participants.

The next step for researchers to improve inclusion of people with disabilities' is to plan for what type of accommodations will be made available. Simple accommodations can enable people with disabilities' to easily complete study activities. For example, deaf participants can have sign language interpreters, blind participants can use text-to-speech technology, people with mobility impairments can participate from accessible spaces, and people with cognitive impairment can use extra time to process information. While accommodations are available for most types of study procedures, it was unclear in the review of published articles to what extent people with disabilities could use accommodations to complete study activities and meet the inclusion criteria. More research is warranted to understand how people with disabilities are accommodated in current research.

Considering inclusion and exclusion criteria as well as offering accommodations will help to include people with disabilities' in the medication adherence research. If this proves too difficult to maintain the homogeneity of the sample or the rigor of the work, then other strategies like specific research oriented towards people with disabilities are necessary.

\section{Limitations}

As this research is based on Cochrane Review on Interventions for Enhancing Medication Adherence, only randomized controlled trials were included in this study. ${ }^{10}$ Therefore, it is possible that lower levels of research may be more inclusive of persons with disabilities. Additionally, the study is limited by the limitations to people with disabilities identified a priori. Further research is warranted to quantify barriers to the participation of people with disabilities identified during this investigative process. Finally, this review only included information present in the published peer-reviewed literature. While authors try to be inclusive of their study procedures, they are often limited by length requirements. Other sources of data collection, such exploratory studies should be investigated to better understand if and how people with disabilities are included in the medication adherence literature. Further, research with people with disabilities related to barriers inclusion in clinical trials would help to identify an inclusive list of barriers to study participation.

\section{Conclusion}

People with disabilities take many medications that are vital for their continued health and wellbeing. Like all populations, many people with disabilities fail to take their medications as prescribed. While there are many studies investigating interventions to promote medication adherence, approximately $30 \%$ of studies explicitly exclude persons based on their ability status. In addition to the criteria that specifically prohibits persons with disabilities, there are other requirements like the use of MEMS caps or use of a certain number of medications that disproportionately affect people with disabilities. 
People with disabilities should be included in all scientifically appropriate intervention studies so that they can have access to safe and effective interventions that promote their long-term health and wellbeing.

\section{Acknowledgments}

Research reported in this publication was supported by the Eunice Kennedy Shriver National Institute of Child Health \& Human Development of the National Institutes of Health under Award Number R03HD097729. The content is solely the responsibility of the authors and does not necessarily represent the official views of the National Institutes of Health.

\section{Disclosure}

Dr Jaclyn Schwartz reports grants from Eunice Kennedy Shriver National Institute of Child Health \& Human Development of the National Institutes of Health, during the conduct of the study. The authors report no other conflicts of interest in this work.

\section{References}

1. World Health Organization. Disability and health; 2020. Available from: https://www.who.int/news-room/fact-sheets/detail/disability-and -health. Accessed March 3, 2021.

2. Kitzman P, Cecil D, Kolpek JH. The risks of polypharmacy following spinal cord injury. J Spinal Cord Med. 2017;40(2):147-153. doi:10.1179/2045772314Y.0000000235

3. Chung P-W, Yoon B-W, Lee Y-B, et al. Medication adherence of statin users after acute ischemic stroke. Eur Neurol. 2018;80(1-2):106-114. doi: $10.1159 / 000493530$

4. Cyrus AC, Royer J, Carroll DD, Courtney-Long EA, McDermott S, Turk MA. Anti-hypertensive medication use and factors related to adherence among adults with intellectual and developmental disabilities. Am J Intellect Dev Disabil. 2019;124(3):248-262. doi:10.1352/1944-7558-124.3.248

5. Frahm N, Hecker M, Zettl UK. Multi-drug use among patients with multiple sclerosis: A cross-sectional study of associations to clinicodemographic factors. Sci Rep. 2019;9(1):3743. doi:10.1038/s41598019-40283-5

6. Gomides APM, Albuquerque CP, Santos ABV, et al. High levels of polypharmacy in rheumatoid arthritis-a challenge not covered by current management recommendations: Data from a large real-life study. $J$ Pharm Pract. 2019;1:897190019869158. doi:10.1177/ 0897190019869158

7. Morgan C, McBeth J, Cordingley L, et al. The influence of behavioural and psychological factors on medication adherence over time in rheumatoid arthritis patients: A study in the biologics era. Rheumatology. 2015;54 (10):1780-1791. doi:10.1093/rheumatology/kev105

8. Remington G, Rodriguez Y, Logan D, Williamson C, Treadaway K. Facilitating medication adherence in patients with multiple sclerosis. Int J MS Care. 2013;15(1):36-45. doi:10.7224/1537-2073.2011-038

9. Ostwald SK, Wasserman J, Davis S. Medications, comorbidities, and medical complications in stroke survivors: The CAReS Study. Rehabil Nurs. 2006;31(1):10-14. doi:10.1002/j.2048-7940.2006.tb00004.x
10. Nieuwlaat R, Wilczynski $\mathrm{N}$, Navarro $\mathrm{T}$, et al. Interventions for enhancing medication adherence. Cochrane Database Syst Rev. 2014;2(11):CD000011. doi:10.1002/14651858.CD000011.pub4

11. Cherubini A, Oristrell J, Pla X, et al. The persistent exclusion of older patients from ongoing clinical trials regarding heart failure. Arch Intern Med. 2011;171(6):550-556. doi:10.1001/ archinternmed.2011.31

12. Clark LT, Watkins L, Piña IL, et al. Increasing diversity in clinical trials: Overcoming Critical Barriers. Curr Probl Cardiol. 2019;44 (5):148-172. doi:10.1016/j.cpcardiol.2018.11.002

13. Duma N, Vera Aguilera J, Paludo J, et al. Representation of minorities and women in oncology clinical trials: Review of the past 14 years. $J$ Oncol Pract. 2017;14(1):e1-e10. doi:10.1200/ JOP.2017.025288

14. Tahhan AS, Vaduganathan M, Greene SJ, et al. Enrollment of older patients, women, and racial and ethnic minorities in contemporary heart failure clinical trials: A systematic review. JAMA Cardiol. 2018;3(10):1011-1019. doi:10.1001/ jamacardio.2018.2559

15. Freedman VA, Spillman BC. Active life expectancy in the older US population, 1982-2011: Differences between Blacks and Whites persisted. Health Aff Proj Hope. 2016;35(8):1351-1358. doi:10.1377/ hlthaff.2015.1247

16. Spong CY, Bianchi DW. Improving Ppublic health requires inclusion of underrepresented populations in research. JAMA. 2018;319 (4):337-338. doi:10.1001/jama.2017.19138

17. Unger JM, Vaidya R, Hershman DL, Minasian LM, Fleury ME. Systematic review and meta-analysis of the magnitude of structural, clinical, and physician and patient barriers to cancer clinical trial participation. J Natl Cancer Inst. 2019;111(3):245-255. doi:10.1093/jnci/djy221

18. Al Mazroui NR, Kamal MM, Ghabash NM, Yacout TA, Kole PL, McElnay JC. Influence of pharmaceutical care on health outcomes in patients with Type 2 diabetes mellitus. Br J Clin Pharmacol. 2009;67 (5):547-557. doi:10.1111/j.1365-2125.2009.03391.x

19. Tilson JK. Validation of the modified Fresno Test: Assessing physical therapists' evidence based practice knowledge and skills. BMC Med Educ. 2010;10(1):38. doi:10.1186/1472-6920-10-38

20. Mullan RJ, Montori VM, Shah ND, et al. The diabetes mellitus medication choice decision aid: A randomized trial. Arch Intern Med. 2009;169(17):1560-1568. doi:10.1001/archinternmed.2009.293

21. Matsumura K, Arima H, Tominaga M, et al. Does a combination pill of antihypertensive drugs improve medication adherence in Japanese? A randomized controlled trial. Circ J Off J Jpn Circ Soc. 2012;76(6):1415-1422. doi:10.1253/circj.cj-11-1481

22. Márquez Contreras E, Casado Martínez JJ, Motero Carrasco J, et al. Therapy compliance in cases of hyperlipaemia, as measured through electronic monitors. Is a reminder calendar to avoid forgetfulness effective? Aten Primaria. 2007;39(12):661-668. doi:10.1157/ 13113960

23. Johnson MO, Dilworth SE, Taylor JM, Neilands TB. Improving coping dkills for self-management of treatment side rffects can reduce antiretroviral medication nonadherence among people living with HIV. Ann Behav Med. 2011;41(1):83-91. doi:10.1007/s12160010-9230-4

24. Bennett H, Laird K, Margolius D, Ngo V, Thom DH, Bodenheimer T. The effectiveness of health coaching, home blood pressure monitoring, and home-titration in controlling hypertension among low-income patients: protocol for a randomized controlled trial. BMC Public Health. 2009;9:456. doi:10.1186/1471-2458-9-456

25. Márquez-Contreras E, Martell-Claros N, Gil-Guillén V, et al. Efficacy of a home blood pressure monitoring programme on therapeutic compliance in hypertension: The EAPACUM-HTA study. $J$ Hypertens. 2006;24(1):169-175. doi:10.1097/01.hjh.000019 8023.53859.a2 
26. Duggan AP, Bradshaw YS, Swergold N, Altman W. When rapport building extends beyond affiliation: Communication overaccommodation toward patients with disabilities. Perm J. 2011;15(2):23-30. doi:10.7812/TPP/11-018
27. Sabatello M. Cultivating inclusivity in precision medicine research: Disability, diversity, and cultural competence. J Community Genet. 2019;10(3):363-373. doi:10.1007/s12687-018-0402-4

\section{Publish your work in this journal}

Patient Preference and Adherence is an international, peer-reviewed, open access journal that focusing on the growing importance of patient preference and adherence throughout the therapeutic continuum. Patient satisfaction, acceptability, quality of life, compliance, persistence and their role in developing new therapeutic modalities and compounds to optimize clinical outcomes for existing disease states are major areas of interest for the journal. This journal has been accepted for indexing on PubMed Central. The manuscript management system is completely online and includes a very quick and fair peer-review system, which is all easy to use. Visit http:// www.dovepress.com/testimonials.php to read real quotes from published authors. 